\title{
Cultivation of the Spirit of Artisan in Enterprise Management
}

\author{
Chunhong Li \\ Business Management Faculty \\ Chongqing Business College \\ Chongqing, China. \\ 106413673@qq.com
}

\begin{abstract}
The spirit of artisan" is significant and becoming more and more indispensable for contemporary enterprise management. Entrepreneurs coordinate and control the system, technology, workflow and other factors in management with the help of this spirit, which is characterized by prudence, commitment to career, meticulousness and perseverance in perfection, in order to further refine enterprise management. Furthermore, an enterprise needs the spirit of artisan to ensure its victory in the long-term competition. On the basis of analyzing why the spirit of artisan is needed and what kind of spirit of artisan modern enterprise management requires, this article emphasizes on discussing the key issue: how to implant the spirit of artisan in corporate management. Only by embracing this spirit in specific aspects including innovative corporate development, acceleration of skillful talent fostering, reinforcement in corporate brand building, improvement in corporate system and building of rational talent assessment system can an enterprise meet subtler requirements with its management, product and service and grow into a role model with consummate product and service.
\end{abstract}

Keywords-management; the spirit of artisan; cultivating; enterprise management

\section{INTRODUCTION}

The Government Work Report of the 2016 incorporates "the spirit of artisan" to encourage enterprises to "cultivate perfection-oriented spirit of artisan, expand product line, improve quality and build brand”. The 2016 Action Plan for Implementing Quality Development Outline, which was issued by the General Office of State Council in Apr. the same year, proposes to "take actions to improve quality and foster the spirit of artisan that is persistent in attaining perfection and improving quality." This era and the development of Chinese enterprises need the spirit of artisan. However, this is more than a slogan but requires enterprises to integrate it into all links of operation and management, which include research and development, design, production and quality, transform spirit into action and offer satisfactory products and services while following a kind of attitude so that the spirit of artisan can serves as a stimulus of corporate development in the real sense.

1,This paper is one of the achievements of 2016 Chongqing social science program "Research of the Spirit of Artisan in New Era and Socialist core Value Building".

2,Chunhong Li, associate professor of economic management

\section{ENTERPRISE MANAGEMENT NEEDS THE SPIRIT OF ARTISAN}

\section{A. Chinese Enterprises Need the Spirit of Artisan to Survive}

The average lifespan of medium and small European and Japanese enterprises is 12.5 years. In America, a relatively competitive country, this data is still up to 8.2 years. However, in China, it is less than 8 years. Secondly, no Chinese enterprise is listed in "The World's Most Valuable Brands for 2016" of Forbes and only less than 20 enterprises are among the Top 100 of "2015 Global 2000: The World's Largest Companies". It can be perceived from the two data that Chinese enterprises are numerous but short-lived with very few being able to rise.

\section{B. Chinese Enterprises Need the Spirit of Artisan to Develop}

Even though some Chinese enterprises are strong, very few of them have world famous brand. Why are Chinese enterprises so short-lived? Why cannot they gain international fame? One of the reasons is their lack of the spirit of artisan. China has attracted the world's attention with its fast development and accumulated sufficient production supply over the past three decades, but Chinese people are anxious and eager for quick success and instant benefits in this era focusing on speed and efficiency. While quickly growing and creating plentiful supply, a majority of Chinese enterprises no longer attach importance to and offer assurance for the quality of supply. As a quality-oriented era is drawing near, it is high time for Chinese enterprises to slow down, contemplate and endeavor to improve the quality of supply by the means of $\mathrm{R} \& \mathrm{D}$, technical innovation, quality control and so on in order satisfy customers and build influential brand. All these require the guidance of the spirit of artisan, which is the spiritual driving force for "Made in China" to transform from "Qualified Manufacturing” to "Premium Manufacturing” and even "Selected Manufacturing" and the supportive factor for China's reform in supply side.

\section{The Demand Side of China's Social Consumption Needs the Spirit of Artisan}

Even though the drastic disparity between the rich and the poor still exists in China, most of Chinese people's consumption level has greatly elevated. The middle class, particularly, can afford better products and goods and pay more and more attention to the quality of life. Over recent years, the products which are enormously popular among Chinese shoppers in their overseas shopping are apparently 
superior to their Chinese counterparts in terms of quality, behind which is the aspiration for the spirit of artisan and humanistic products. The fruit of this aspiration is a wonderful and irresistible user experience. Whoever uses a product embodying the spirit of artisan will become its loyal customer.

\section{Chinese Enterprises with Brand have Succeeded in Putting the Spirit of Artisan into Practice}

The corporate culture of many time-honored Chinese enterprises reflects a strong spirit of artisan. Tongren drug store's couplet "Processing is always amply manned no matter how complicated it is; raw materials are always generously used no matter how expensive they are" is both unforgettable and admirable. Huawei applies some interesting slogans like "Do not fool Lei Feng”, "Any bird that cannot be burnt to death is a phoenix" and "Be prepared to be overlooked for ages" to pre-employment "general teamwork training” (its offjob corporate culture training) and learning manuals to induce employees to learn and think. These simple and catchy slogans aim to instruct employees to overcome anxious mood and be concentrated on work. In addition, some successful Chinese enterprises hang banners like "Continue to match toward perfection - our core values" and "Producing low-quality product is equal to generating garbage" in their workshops and offices. It is desirable that more and more enterprises infuse the spirit of artisan into the sub-cultures of product, quality, production, $R \& D$ and so on in their corporate culture.

\section{THE SPIRITUAL CONNOTATION OF ARTISANS IN ENTERPRISE MANAGEMENT}

The purpose of enterprise management is to greatly enhance the efficiency of enterprises, to have a clear direction, to give full play for employee, to provide customers with products and services, thereby enhancing the competitiveness of enterprises. To talk about enterprise management from the spirit of artisans, is helping employees to achieve excellence, rigorous, professional and dedicate through the enterprise management. From the enterprise management level, the spirit of artisans is excellence. This spirit works in business management, similar to others, complement others. Employees in this world of temptation and impulsive always keep calm and adhere to excellence and focus, so the enterprise will be survival in the sustainable development. The spirit of artisans in enterprise management level mainly shows in the following four aspects:

\section{A. The Spirit of Artisan is the Spirit of Innovation and Professionalism}

Enterprises need to be led by spirit of the artisan and put it into production and management. By investing labor, financial, and material, so production, research and development, technology, hardware and software environment can be continuously improved. Then absorb cutting-edge technology, create products and build brand. From product innovation to innovation of technological, market, organizational etc. enterprises find new business opportunities, and have dividend, then continue to invest that promotes innovation which makes a virtuous circle. While with professionalism, enterprises will have an inexhaustible motive force, in order to make products, companies have competitiveness. Considering the requirements of the times and understanding the essence of artisans, enterprises achieve their own path and methods of artisans in order to achieve enterprise supply quality improvement, the realization of the enterprise everlasting ${ }^{[1]}$.

\section{B. The Spirit of Artisan Leads the Technological Innovation}

Innovation is an important connotation. Original technology innovation and application of new technologies will better meet customer needs; enhance the user experience for customers with higher value. Artisan spirit not only embodies the concept and pursuit production, but also to actively absorb cutting-edge technology and keep making progress through the application of new technologies. Under the guidance of the spirit of the artisan, R\&D and innovation need to consider whether it is willing to bring value to customers, to withstand $\mathrm{R} \& \mathrm{D}$, to make excellent selection from hundreds of programs, to make performance improvement, to pursuit of a new height, and ultimately give consumers stunning products. In addition, the technology heritage and innovation come from the original good technology heritage and innovation, that ultimate goal is to enhance the quality, constant pursuit of perfection and give users a better experience which is the insistence of the spirit of the artisan.

\section{The Spirit of Artisan Leads the Quality of Management}

Quality management needs to be led by the quality of cultural and quality management system. It needs ideological and institutional building. Quality culture allows enterprises to form a common quality concept, in the formation of the pursuit of the ultimate quality of the spirit. Quality systems need rigid requirements, product quality standards need to be strengthened and enhanced, and quality concepts need to be promoted in all aspects. In quality management, Huawei and Gree have a good experience worthy of domestic enterprises to learn. Huawei insists that more than $10 \%$ of its sales revenue will be used for $R \& D$, and get more than 38,000 patents. Huawei will sell its products to more than 170 countries and regions. Huawei's "customer-centric" values expounded the connotation of the spirit of artisans, which is the best voice of Chinese quality. Gree is the only one who masters the "frequency compression technology", with more than $8,000 \mathrm{R} \& \mathrm{D}$ personnel is recruited by Mingzhu Dong from colleges and universities. Research and development inputs, and control of core technology perseverance, artisan spirit can be fully reflected ${ }^{[2]}$.

\section{The Spirit of Artisan Improves the Quality Level of Staff}

Today, the practice of artisan spirit is not making employees engaged in handicrafts, but how to place the spirit of craftsmen into the production and operation management practices, and promote product quality. This requires that every employee can be the spirit of artisans to treat their work, strict demands on themselves. They are willing to spend more time to study, to work hard, to take the initiative to learn and update knowledge and innovation. If they are pursuing perfection, employees will become expert-type talent. 


\section{The LeVel of Enterprise Management NeEdS to BE IMPROVED}

Currently, Chinese enterprises are at the critical period of transformation and upgrading as well as international strategy, it is important for enterprises to develop personalized customization and flexible production and foster excelsior spirit of the artisan. It concerns construction of core value, sustained and healthy development and assumption of responsibility of enterprise.

\section{A. Promoting the Innovation of Enterprise with Spirit of Artisan}

Enterprises should be conscientious and need to strengthen and improve quality guarantee system, enhance the awareness of quality and responsibility and focus on strict quality standard as well. "Spirit of artisan" represents the pursuit of perfection on everything while "spirit of innovation" represents great exploration of new ideas and new things. Besides, innovation of management and technique would not emerge if enterprise lose "spirit of artisan" and do not strive for excellence. Furthermore, in order to inspire innovation, enterprises should set up "innovation studio" in primary-level organizations and create innovative platforms for technology research and development. And combining "spirit of artisan" and "spirit of innovation", improving integrated management and technology innovation system, which enhance innovation ability and cultivate innovative product in terms of reform and development, technical improvement and lower cost and higher profit ${ }^{[3]}$.

\section{B. Accelerating Skilled Talents Training with Spirit of Artisan}

The talents with skills play key roles in promoting technological innovation and technology transformation. Moreover, the enterprises should put talents into the first place, strengthen the effort in personnel training and give prominence to professionalism and practicability in terms of producing, management and service, forming a training system of managerial talents, professional and technical talents, and talents with high skilled produce and service ability, which provides space and platform for talents to develop. Additionally, enhancing the training of skilled talents and creating a professional and dedicated group of skilled workers that is a significant measurement to accelerate industrial upgrading and transformation ${ }^{[4]}$. Therefore, the enterprises must reinforce the strategy of "developing the enterprises with science and education, and with talents", combine the spirit of artisan and skilled talents training, and create a great skill learning atmosphere, develop staff "quality project" through skill training and competition, which offers personnel guarantee for reform and development, and production and management ${ }^{[5]}$.

\section{Enhancing Enterprise Brand Building with Spirit of Artisan}

In order to establish brand strategy, enterprise should build the idea of quality brand. Brand building cannot be separated from "originality" and enterprise should understand the importance of the strategy of brand building in market competitions. And then understanding the market fully, establishing core competitiveness and implementing brand strategy. Additionally, producers who have the spirit of artisan should show respect to consumer and do not treat consumer as experiment and do not let rejected product flow into market. Moreover, enterprises, with spirit of artisan, should resist loneliness and withstand temptation of interests, conform to the ideas of "ten years for sharpening a sword" and "to do one thing in the lifetime” and focus on long-run development. In terms of enterprise innovation, enterprise must focus on customers and find the way to increase efficiency and decrease the cost of quality, and it should be back to the origin.

\section{Perfecting Construction of Enterprise Institution with Spirit of Artisan.}

There is no guarantee that employees will still keep their working standards, and it leads to unstable achievements without strict requirements, measures and regulations. Meanwhile, it is difficult to achieve excellence if lacking of promoting standard and external pressure from continuous improvement. Enterprise must follow the objective of excellence and strict requirements, which increases employees' skill levels and enhances their professional skills and improves product and service quality. Besides, it is necessary to make a good atmosphere where people can be encouraged to work seriously, to bear their responsibilities, to take everything into consideration and do a detailed work. In addition, reasonable evaluation system and incentive policies should be introduced to establish relevant mechanism and measurements and requirements for "spirit of artisan" should be manifested to influence actual work performance of employees, which allows employees to understand the power of culture. Also, according to modern management concepts, enterprise needs to improve quality management system and technical headstream management and ensure advancement, reliability and maturity of products and technique.

\section{E. Building Rational Talents Evaluation Mechanism with Spirit of Artisan}

That people are not willing to be workers is observed among the normal because of low income and occupational reputation and exist of official-centered concept as well. Besides, in order to enhance social status of workers, a concept that respecting, approving of and becoming skilled talents should be formed. Enterprise managers need to know that high-skilled talents and classic product design are not enough; great production technology and artisan-like skilled talents are indispensable. The role and contribution of highskilled talent in the economic construction should be recognized, which increases skilled workers' social status and occupational reputation. Also, income should be increased for outstanding skilled workers and promotion blueprint should be introduced for young people as well. Furthermore, enterprise would not reach the target or play a leading role if ignoring "spirit of artisan" and the support from outstanding skilled workers. Income of excellent workers should be increased and then they can concentrate on work and not worry about livelihood. In addition, a promotion channel should be introduced to encourage young workers to have a well development. It is also important to improve evaluation system and reward system of skilled talents. And outstanding 
skilled talents should be selected among the enterprise, and set them as models of spirit of artisan.

\section{CONCLUSION}

The "spirit of the artisan" is not only represents a new concept of produce, but also represents the direction of transformation of Chinese enterprises and "Made in China". Stepping out from the mud of low-end manufacturing, eliminating backward production capacity, strengthening technology innovation, and their ultimate aims is to increase the variety, to improve the quality, to creates the brands, and update the overall level and image of Chinese enterprises. However, shouting the slogans is not enough for Chinese enterprises to achieve the spirit of artisan; the most significant thing is to put the spirit of artisan into practice. "Unity of knowledge and practice" makes the "spirit of the artisan" to help the development of Chinese enterprises.

\section{REFERENCES}

[1] Xue, Dong, "On the value meaning of the ancient Chinese spirit of the artisan,” [J]. Vocational and Technical Education Forum, pp.94-96, 2013(34).

[2] Shou, Yong, "The spirit of the artisan: Evolve to value employees," [M]. Beijing: All China national industry and commerce association press, 2013.

[3] Wang, Li, "Calling upon the spirit of the artisan," [J]. Construction Enterprise Management, p.100, 2015(5).

[4] Guo Qing, "Inherit the traditional process essence and cultivate the modern spirit of the artisan," [J]. Theories and the contemporary era, pp.41-42, 2015(7).

[5] Chen Changhui \& Liu Shu, "The spirit of the artisan----'Made in China' calls upon the vocational education to undertake,” [J]. Occupation, pp.14-15, 2015(20). 